\title{
Author Correction: Salt concentration and charging velocity determine ion charge storage mechanism in nanoporous supercapacitors
}

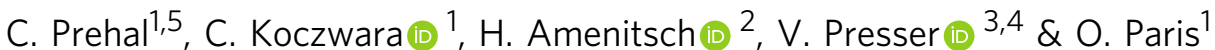

Correction to: Nature Communications; https://doi.org/10.1038/s41467-018-06612-4; published online 08 October 2018

The original version of this Article contained an error in the Acknowledgements, which was incorrectly omitted from the end of the following: 'The research leading to these results has received funding from the European Community's Horizon 2020 Framework Programme under grant agreement $n^{\circ}$ 730872.' This has been corrected in both the PDF and HTML versions of the Article.

Published online: 11 January 2019

\begin{abstract}
(c) (i) Open Access This article is licensed under a Creative Commons Attribution 4.0 International License, which permits use, sharing, adaptation, distribution and reproduction in any medium or format, as long as you give appropriate credit to the original author(s) and the source, provide a link to the Creative Commons license, and indicate if changes were made. The images or other third party material in this article are included in the article's Creative Commons license, unless indicated otherwise in a credit line to the material. If material is not included in the article's Creative Commons license and your intended use is not permitted by statutory regulation or exceeds the permitted use, you will need to obtain permission directly from the copyright holder. To view a copy of this license, visit http://creativecommons.org/licenses/by/4.0/.
\end{abstract}

(C) The Author(s) 2019

\footnotetext{
${ }^{1}$ Institute of Physics, Montanuniversitaet Leoben, Franz-Josef Straße 18, 8700 Leoben, Austria. ${ }^{2}$ Institute of Inorganic Chemistry, Graz University of Technology, Stremayrgasse 9/IV, 8010 Graz, Austria. ${ }^{3}$ INM-Leibniz Institute for New Materials, Campus D2 2, 66123 Saarbrücken, Germany. ${ }^{4}$ Department of Materials Science and Engineering, Saarland University, Campus D2 2, 66123 Saarbrücken, Germany. ${ }^{5}$ Present address: Institute for Chemistry and Technology of Materials, Graz University of Technology, Stremayrgasse 9/V, 8010 Graz, Austria. Correspondence and requests for materials should be addressed to C.P. (email: christian.prehal@tugraz.at) or to O.P. (email: oskar.paris@unileoben.ac.at)
} 